\title{
SHIFTING SANDS ON DIFFERENTIATION AND SPECIALISATION IN HIGHER EDUCATION IN SOUTH AFRICA
}

\author{
I. M. Ntshoe \\ Central University of Technology \\ Bloemfontein, South Africa \\ e-mail: intshoe@cut.ac.za
}

\section{J. M. Selesho}

Vaal University of Technology

Vanderbijlpark, South Africa

e-mail: jacobs@vut.ac.za

\section{ABSTRACT}

This article examines shifts in, and variations of, differentiation, diversification and specialisation and their impact on missions and mandates of different institutional types in South Africa. It explores patterns and how these might encourage institutional 'mission drift', arguing that, in practice, institutions are positioned on a continuum. While legally mandated institutional boundaries are still common, there is increasing support for the blurring of these boundaries because of changing conditions in the new economy. Mission drift could be attributed to the decline in government funding, increasing private contribution and entrepreneurship.

Key words: differentiation, diversification, specialisation, mission drift, purposes and mandates, differentiation creep.

\section{INTRODUCTION}

The Fordist and post-Fordist episteme generally espouses contrasting conceptions and assumptions on the types of society, trade and economic models of production, the nature of employment and manufacturing and the types and organisation of workforce during these periods. Fordism describes a model of economic expansion and the technological progress of industrialisation based on mass production, and the manufacture of standardised products in volume, using special purpose machinery and unskilled labour. Three major features of this episteme are: 1) The standardisation of the product whereby everything is made through machines and moulds, rather than by skilled craftsmanship; 2) The use of special-purpose tools and/or equipment designed to make assembly lines possible and usable by workers with basic skill levels; 3) Workers are paid higher living wages, so they can afford to purchase the products they make (Tolliday and Zeitlin 1987, 1-2).

The post-Fordist episteme, on the other hand, covers postmodern society in which 
production is smaller, class-based, characterised by new information and technology, and operates in globalised financial markets. It faces increased international competition for goods and labour, new technological innovations, and the movement from mass production to 'diversification specialisation' in the production process (Castells 1993, 15-18). This period is almost universal, and includes the dedifferentiating use of digital technologies, an increasing emphasis on generic skills that are assumed to apply to very different occupational sectors, and jobs, rather than the specialist skills and knowledge associated with particular jobs and occupations (Castells 1993; Chappell, Solomon, Tennant and Yates 2002). However, while it is theoretically possible to distinguish between earlier conceptions of differentiation and specialisation, the contrasting flexibility and peculiarity of each is somewhat blurred in practice.

While the above narrative describes the organisation of the workforce in trade and industry during the Fordist and post-Fordist epistemes, policy and practice on differentiation, diversification and specialisation in higher education have borrowed some ideas from the trade and industry models of the two epistemes. Two contrasting conceptions of differentiation and specialisation in higher education are:

how the range of heterogeneity or homogeneity is preferable; the extent to which diversity should be arranged inter-institutionally or intra-institutionally; how clearly differences should be demarcated or soft and blurred should be the differences; iv) whether diversity prevails predominantly according to the vertical dimensions, such as ranking according to quality or reputation, or whether horizontal differentiation, such as according curricular thrusts and institutional profiles, plays a role as well. (UNESCO 2004, 5).

Similarly, discussions on differentiation and specialisation raise the following questions posed by Reichert (2009, 9). Thus:

How might national higher education systems and institutions answer such diversity of demands, while still responding to an increasingly interconnected world in which nations, institutions and individuals compete internationally for higher education resources? What kinds of incentives should higher education systems and individual institutions provide for these diverse needs and functions? Should they promote more differentiation of institutional profiles, in terms of functional emphases or missions, or subject area specialisation?

We deployed the sociology of knowledge approach to embed discussions on differentiation, diversification and specialisation in higher education sectors globally, and specifically in South Africa. Our article explores competing prototypes of differentiation and diversification and how these patterns and variations play themselves out in practice in different contexts. The article examines how shifting patterns and variations are shaping missions, mandates, foci and the 
purposes of institutional types in changing times. It also investigates 'mission overload', 'mission stretch', 'mission creep’ and academic 'mission drifts' in differentiated and diversified systems.

\section{THEORETICAL STRANDS}

Differentiation, specialisation and the division of labour formed the hallmark of trade and economic of the Fordist episteme, central to which was a rigid distinction among products with the explicit motive of encouraging competition, hard work and efficiency (see Ntshoe 2014). Specialisation, usually associated with differentiation, is a strategy of traditional trade models championing specialisation in the production of goods to strengthen the comparative advantage of firms. Thus, specialisation is one of the few activities that reduces production costs, and is often associated with an increase in production (Smith 1776; Durkheim 1983; Kaulich 2012, 2). In contrast to rigid differentiation and specialisation, diversification describes a process of modifying and exploring new markets and prospective new consumers and clients (Kogut and Zander 1993).

Diversification in the economy therefore refers to the process in which a growing range of economic outputs is produced and encompasses the diversification of markets for export, or the diversification of income sources away from the domestic economic activities of countries.

Intrinsic to differentiation and specialisation is the division of labour. The underlying belief is that the increasing production, maximisation of efficiency and cost-effectiveness in production could be promoted through the division of labour. Durkheim (1983) argues in one of his seminal works that, whether or not explicitly stated, all societies reflect some division of labour that positively correlates with societal advancement, because it increases as a society progresses. Thus, the credential society emerged with increasing specialisation and the division of labour (Collins 1979). However, while earlier conceptions of differentiation and the division of labour were generally accepted features of agrarian societies, these were challenged on two fronts by more nuanced conceptions of flexible diversification and specialisation in the second, post-Fordist half of the twentieth century. First, earlier conceptions generally underplayed 'the way in which production was sustained; thus, technological improvement came about' (Winch 2006, 369). Second, these conceptions are generally silent on economic changes, skills emerging in new manufacturing and innovation practices that increasingly characterise current economic production.

Rather than celebrating differentiation and specialisation in production, flexible differentiation and specialisation (also the neo-Smithian approach) assumes that fundamental 
changes in the international economy, especially in the early 1970s, compelled firms to switch from mass production to a new tactic, known as ‘diversification specialisation' (Cristopherson and Storper 1989). This type of differentiation therefore emphasises similarities between different occupations, knowledge and skills, and assumes that the primary source of innovation is a growing supply of generically-skilled workers, able and willing to move to new jobs, regions, countries, industries and services, as and when they arise (Jones 2009).

Flexible differentiation underscores employment, opportunities for specialisation by small firms, the production of new goods and services, accommodation of new manufacturing and the changing nature of employment. In contrast with the rigid division of labour of the Fordist episteme, flexible differentiation and specialisation call for the soft and flexible division of labour, prioritising diversity to address the needs and requirements of modern society which is characterised by an 'increasing variety of specialisations in the labour market necessary for economic and social development' (Huisman 1995, 51; Van Vaught 2007, 5; Ntshoe 2014, 678).

Likewise, a distinction is made between differentiation and diversification on one hand, and specialisation in binary systems on the other. The latter prevailed in traditional universities, which distinguished themselves from other institutions offering higher education (HE) academic programmes, with flexible differentiation and diversification tempered by the partial or total abolition of binary policies and practices. In terms of our conceptualisations above, differentiation, in which purposes and mandates of institutional types are clearly distinct, is analogous to earlier conceptions of differentiation and rigid specialisation in economic production. Conversely, flexible differentiation, diversification and specialisation describe practices in which distinction between the purposes, mandates and foci of institution types is blurred. Differentiation in HE may:

occur vertically when distinct types of institutions appear, as the traditional research university is joined by polytechnics, professional institutes, non-research universities, and junior colleges. Vertical differentiation is normally a reaction to labour market needs for a greater diversity of graduate skills and levels of training. Horizontal differentiation, on the other hand, is generally a response to increased demand for student access to HE. (Ng'ethe, Subotzky and Afeti 2008, XVII).

Differentiation, according to Van Vught $(2007,2)$ is 'the process in which new entities emerge in a system [of HE that signifies] the variety of entities within a system'. Van Vught $(2007,2)$ uses Birnbaum's (1983) typology that 'distinguishes between external diversity (a concept which refers to differences between HE institutions), and internal diversity (differences within HE institutions)'. Diversity is assumed to better serve the needs of the labour market, offer more 
and better access to a larger student body and allow institutional specialisation through which the effectiveness of the overall HE system increases (Republic of South Africa 2014, 7-9).

\section{CONCEPTIONS OF DIFFERENTIATION, SPECIALISATION AND DIVERSIFICATION}

Two propositions by Young and Moodie provide a useful frame for differentiation, specialisation and diversification in this article (2012). The first is that specialisation provides the basis for the creation of new knowledge, better products and better services, and that in education the price for knowing more about less is worthwhile both for the individual and society. One of the expressions of such specialisations and the inequalities associated with it is the academic - vocational divide (Young and Moodie 2012). The second relates to developments in the disciplinary specialisation of knowledge and knowledge boundaries. The emergence of biochemistry as a separate discipline and its strong growth in the late 20th century that led to its institutionalisation as a separate department or unit within many universities is but one example (Young and Moodie 2012). These two propositions further provide a scaffold with which to examine the missions, purposes and mandates of the different institutional types.

Missions essentially 'drive the programmes, the kinds of students attracted, faculty appointed and the expectations upon them, and the way the institution is or would be assessed' (Johnstone 1998, 3). Some mission differentiation prevalent in HE includes: 1) Performancebased differentiation, referring to maintaining and even increasing diversity of HE systems, where different ranking instruments need to be developed in which different forms of institutional performance can be compared; 2) self-differentiation, describing a process based on varied institutional visions, missions, policies and practices that enable institutions to meaningfully progress in a distinct development path. It can also be seen as institutions evolving within and across various categories in complex and dynamic ways; and 3) programme differentiation, representing differentiation that may be considered at the level of programmes, as well as institutions in which the primary differentiator is programme purpose.

Following the descriptions above, until recently,

most HE systems were divided along binary lines involving clear distinctions between categories of institutions, such as research universities, liberal colleges and vocational colleges, and between types of institutions within the same categories, such as teacher, engineering and nursing colleges in terms of missions, purposes and foci. (UNESCO 2004, 20).

Within binary policies, the mission orientation of research universities advances scholarship and training associated with the classical research university. On the other hand, in a binary 
setting are institutions oriented towards accessibility, vocational training, and the offering of short-cycle programmes associated with what sometimes are referred to as non-university institutions (Johnstone 1998).

Johnstone observes that non-university institutions usually have missions, foci, purposes and mandates to address local and regional mandates and aspirations. These institutional types, in most countries, 'lie somewhere between the extremes of the classical, research-oriented, Humboldtian university, and the exclusively short-cycle, teaching and vocationally oriented college or institute' (1998, 3).

Flexible differentiation (dedifferentiation) associated with the post-Fordist episteme challenges the fundamental assumptions of Fordism, including the tendency to the specialisation of results in divisions and the alienation of workers. This assumes specialisation could take a more flexible than divisive form, in line with the scientific management theories of F. W. Taylor (Piore and Sabel 1984; Reich 1991; Young and Moodie 2012). In particular, flexible differentiation is commonly maintained in the context of the changing nature of employment and the emergence of new manufacturing and products, thus increasing the move towards diversification and the blurring of differences and boundaries between institutions, sectors and intellectual fields.

Flexible differentiation and specialisation take both a horizontal form, as in the case of the expansion of multi- and trans-disciplinary programmes, and 'smorgasbord' modular programmes that allow students to select a variety of subjects without concentrating on any. It may also take a vertical form whereby, for example, colleges offer both school and university level programmes. (Powell and Solga 2010, 708 and 715).

Flexible differentiation (dedifferentiation) in essence, amounts to a 'blurring of older divisions of vocational or professional, and the emergence of overarching organisational categories such as “tertiary” and "higher” education rather than universities' (Bleiklie 2005, 48; Teichler 2004). A typical instance of is the general support for a qualifications framework which relies on a common 'generic' model of a qualification discourse prevalent in most systems (Lester 2001; Centre for the Development of Vocational Training (EDEFOP 2010; Allais, Raffe and Young 2009). This 'homogenising' of previously distinct qualifications within a single model with a single set of level descriptors is paralleled by the growing emphasis on generic rather than specialist skills and knowledge. The assumption is that new knowledge and skills are developing so fast that any existing knowledge or skill quickly becomes obsolete. The new generic capabilities are assumed to be resources for generating new knowledge and therefore will not become obsolete. However, flexible specialisation is not without challenges, identified 
by Young and Moodie (2012) in the clear differentiation of qualifications and a prioritisation of specialisation (and thus, boundaries), which is more consistent with such a scenario than the blurring of boundaries to support greater flexibility. This can only weaken the conditions for developing specialist knowledge.

\section{DIFFERENTIATION, DIVERSIFICATION AND 'MISSION DRIFTS'}

Generally, the growth of universities around the world is a product and an expression of the division of labour or the division of specialisation. Clark (1983) and Trow (1974) argue that the growing division of labour among institutions of higher education (IHEs) is usually welcomed to meet increasing diverse needs of individual students and societies. The implicit division of labour in HE is more pronounced in systems that retain binary policies in general, such as the Norwegian HE system, thus:

while one comprehensive law governs this system, essentially it is binary in its division of labour between research-based universities and other institutional types. Within the comprehensive law, therefore, research-based universities in the Norwegian differentiation system are permitted to choose freely the programmes they may wish to include in their curricula. Conversely, 'other education-oriented university colleges have to undergo accreditation if they wish to move up the Bologna ladder to offer master’s courses, and even PhD programmes’. (Reichert 2009, 63).

A widely-held belief, until recently, has been that within the rubric of public higher education would be an array of types of institution, each with a clearly designated mission, and a clear expectation that whilst they would seek excellence, they would do so within their designated mission. In terms of this designated mission, in the United States of America (USA) institutions are classified into three categories, namely, community colleges, baccalaureate colleges or universities, and research universities (Longanecker 2008). Diversification in HE is generally adopted to counteract the negative impact of isomorphism, that is, the imitative and aspirational behaviour which occurs when institutions adopt similar features, notably those of the research university, in order to achieve strategic advantage, higher status and better quality. 'This aspirational behaviour is associated with "academic drift” among non-university polytechnictype institutions, i.e. the process in which the latter gradually take on the trappings of universities' (Ng'ethe, Subotzky and Afeti 2008, 6).

In practice however, both traditional universities and other types of institutions, at some point or another, tend to drift away from their original missions, purposes and mandates towards missions of other institutions. 'Mission drift' refers to the gradual drift away from their original mission, foci and specialisations in the knowledge and skills production process, towards 
missions, and specialisations of other institutional types. For example, universities usually become involved in vocational drift, by creeping in the missions and offering vocational courses and short-cycle options in competition with other institutional types (Ross 2003). Accordingly, vocational drift emerged under conditions of a tight graduate labour market and general pressures for the growing practical relevance of HE (Neave 1996; Williams 1985).

Usually, 'institutional orientations and profiles reflect the diversity (or homogeneity) of the environment and its influencing forces' (Reichert 2009, 8). 'These influences may derive from the practices and developments of science and scholarship itself, i.e., the demands of disciplinary and labour market specialisation and differentiation' (Reichert 2009, 8). They may also derive from state regulation, funding sources and instruments, or from the reward structures within higher education systems (Clark 1983). The combination of diverse needs, in many cases, results in institutional resources being spread thinly over a wide range of missions, and such mission spread may result in 'mission stretch' or even in 'mission overload' that may be threatening to institutional coherence, integrity and efficiency (Scott 2007). Thus, in competing for limited resources with other institutions, and in responding to their key stakeholders, norms and values, institutions (or units within them) feel compelled to prioritise some dimensions over others, i.e. those which they feel will most easily provide access to resources and rewards.

Diversity in higher education is normally supported because, first, 'a more diversified system offers access to students with different educational backgrounds and with varied histories of academic achievements and preparedness' (Van Vaught 2007, 6). Thus, a 'diversified system, in which the performance and quality of the institutional types varies, each student is offered an opportunity to work and compete with students of similar background ... they all have the opportunity to find an educational environment in which chances for success are realistic and achievable' (Van Vaught 2007, 6). Second,

diversity facilitates social mobility, progression and/or articulation. By offering different modes of entry into HE and by providing multiple forms of transfer .... A diversified system allows for corrections of errors of choice; provides extra opportunities for success; rectifies poor motivation; and broadens educational horizons. (Van Vaught 2007, 6)

Third,

diversity addresses needs of the labour market. In modern society an increasing variety of specialisations in the labour market are necessary to allow further economic and social development. A homogeneous education system is thought to be less able to respond to the diverse needs of the labour market than a diversified one ... diversity serves the political needs of interest groups, ensuring the needs of different groups in society to have their own identity and political 
legitimation .... Generally speaking, mass systems tend to be more diversified than elite systems, as they absorb a more heterogeneous clientele and attempt to respond to a wider range of demands from the labour market. (Van Vaught 2007, 5)

In his analysis of mass and elite systems, Trow (1974) indicates that the survival of elite higher education depends on the existence of a comprehensive system of non-elite institutions. Essentially, it is argued that only if a majority of the students were offered the knowledge and skills relevant to finding a position in the labour market would a few elite institutions be able to survive. Fourth, 'diversity is assumed to increase the level of effectiveness of all institutional types' (Van Vaught 2007, 5), an argument consistent with the Carnegie Commission (1973) which has suggested that 'institutional specialisation allows education institutions to focus their attention and energy, thus helping them to produce higher levels of effectiveness' (Republic of South Africa 2014, 11).

Despite some of the optimism outlined above, Neave (2000) argues that using differentiation to set up an alternative sector to that of the university is generally problematic, as it is driven by the market and not by student or community needs, with negative, unintended consequences (Neave 2000). Conversely, 'different types of institutions or the individual institution, may not necessarily be eager to serve a variety of needs, but rather aim to stabilise themselves so as to increase their status by getting closer to the most successful institutions' (Teichler 2004, 9; Williams 1985).

Competing perspectives exist on what constitutes 'mission drift', why it occurs, and its effects on practice. Johnstone $(1998,7)$ ascribes the drift to 'conventional reform agendas in the production of knowledge that have involved the incorporation of greater differentiation and diversification as opposed to diversification differentiation, to forces of academic drift and institutional homogenisation'. Bleiklie (2005, 48), on the other hand, attributes diversification and 'academic drift' to the logical consequences of the blurring of older divisions of occupations and professions, and the emergence of overarching organisational categories, such as tertiary and higher education rather than universities. Mission drift and creep could also be attributed to the increasing demand for higher education and entrepreneurship as institutions expand their original missions and mandates.

In public policy circles, as with many other issues, two camps have emerged on how institutions may seek to expand their mission. Some believe that mission creep resembles an invasive species, that is, it is evil, adapts readily to the environment, and expands voraciously, crowding out everything that is good.

For others, it is an inevitable and positive development that allows institutions to grow, consistent 
with the growing needs of their communities ... Typical examples are community colleges seeking to become baccalaureate colleges, baccalaureate colleges seeking to become universities, modest universities seeking to become significant research universities, and research universities seeking to become world class. (Longanecker 2008, 2).

Riesman (1965) blames increasing diversification for causing gravitation in the higher education sector which in turn, undermines the differentiation and diversification of the purposes of institutions in the US system. This was 'compared to a kind of reptilian procession during which certain HE institutions move to the positions where other institutions were before 1965' (Van Vaught 2007, 7). Van Vaught (2007, 7) describes this procession as representing the typical behaviour of HEIs which mainly consist of lower status institutions trying to gain status by imitating higher status institutions. Dedifferentiation and the corresponding mission drift could also be ascribed to centralised state-level planning and the application of rigid criteria for the approval of new institutions (Birnbaum 1983). According to this view, 'governmental policies may be a contributory factor in producing processes of dedifferentiation and decreasing levels of diversity, especially in the prestigious research universities' (Van Vaught 2007, 7).

Two propositions about mission drift are in order. First, organisations adapt to general conditions perceived as being successful when faced with scarce resources which lead to greater uniformity. In the current context, faith-based institutions may seek to appear similar to public institutions, by, for example, identifying themselves as universities. Second, is the pursuit of reputation, defined by Van Vaught $(2007,17)$ as 'the subjective perception of the quality, influence, and trustworthiness of an institution, is important in understanding change in HEIs'. Mission drift is widespread in systems in which HE is rigidly differentiated into research-based, teaching institutions and others that prepare students for the application of research relevant to local and regional needs. In comparison with other countries, Johnstone makes the useful observation that

Brazilian universities, like their French counterparts, on which they were largely modelled, have traditionally been teaching institutions rather than centres of scholarship or research scholarship. Consequently, little seems to be gained from taking on the designation of 'university', since most Brazilian universities already operate primarily as teaching institutions. (Johnstone 1998, 7).

Other commentators attribute the decrease in diversity and the increase in homogeneity and similarities to the process of isomorphism, referring to natural organisational behaviour in response to their environments (DiMaggio and Powell 1983; Van Vaught 2007). Van Vaught goes further to argue that 'coercive isomorphism results from the pressures applied by other 
organisations in the environment, on which the organisation is dependent, such as governmental policies and laws’ (2007, 11). Borrowing from Van Vaught, Muller argues that isomorphism could be minimised through 'performance contracting', as institutions are expected to commit to a particular focused teaching and research niche and set of performance targets, with attendant inducements and sanctions attached (Muller 2014). Ng'ethe et al. (2008, 32) argue that 'isomorphism occurs when newer universities fashion themselves on older ones, or where newer polytechnics are simply copying the programme of older ones. Isomorphism is likely to be worse in poorly regulated HE systems because the individual institutions have the liberty, by default, to stray from their original mandate’.

\section{SOUTH AFRICAN CONTEXT}

In South Africa, differentiation prior to 1994 epitomised political, ideological and economic imperatives of the 'separate but equal policy and practice'. During this period, the HE sector was organised along binary lines, which differentiated between universities, the erstwhile technikons, and technical colleges representing the post-school sector. Institutional differentiation reflected government policy that created historically advantaged universities (HAUs) and the technikons on one hand, and historically disadvantaged universities (HDUs) and technikons on the other hand (Department of Education (DoE) 1997a). HAUs provided high-level knowledge and skills in subjects associated with economic and political power, including Science, Technology, Engineering and Mathematics (STEM) (Ng'ethe et al. 2008, 118). Similarly, the geopolitical boundaries confined HDUs to the former homelands in rural areas, and were intended to produce graduates mainly in Social Sciences to consolidate the 'separate but equal' policy (Ng'ethe et al. 2008, 15, 16).

Erstwhile technikons during this period were created firstly to prepare people to practice, promote and transfer technology within a particular vocation or industry and secondly, to educate students for the practice of a particular vocation, or set of related occupations in industry (Department of Education 1997b). The curricula were intended explicitly to prepare a graduate for a particular job, and were then put together as modules and courses which provided the candidate with the necessary skills, information, ability and training (Du Pre 2009). The emphasis for technikons was on application of knowledge, rather than on knowledge itself, and students were to be less concerned with abstract thinking and scientific approaches to knowledge than were university students (CHE 2002; Cloete and Bunting 2002). Similarly, universities during the apartheid era were not expected to become involved in technology, in the sense of the application of knowledge, and technikons could not become involved in 
scholarly activities involving the generation of new knowledge prior to the 1994 democratic elections (CHE 2000; Cloete and Bunting 2002). However, the continuation of the strict binary divide and the narrow interpretation of polytechnic or technikon training has been criticised as 'being technicist and divisive, particularly in South Africa' (Ng'ethe et al. 2008, 122). This narrow interpretation tends to inhibit debate on important issues such as equity, access, mobility and the relationship between education and training in general.

Differentiation in the post-1994 setting in HE in South Africa is the product of the partial abolition of the binary policy system between universities and technikons (Council for Higher Education (CHE) 2000). Differentiation is intended to address the new political, social and economic requirements of the post-apartheid society, while also responding to inevitable globalisation (Human Sciences Research Council 1996; DoE 1997a). However, the wholesale abolition of the binary policy was rejected and rather, a modified version of a number of institutions was proposed (DoE 2001).

Institutional differentiation in South African higher education has expressly been introduced as a strategy to promote effective responses of institutions to the varied social needs of the country (CHE 2000, 64). It is recommended because it allows for specialisation and for the more focused and targeted pursuit of educational and social goals, foci, mandates and purposes (CHE 2000). The underlying assumption was that differentiation guarantees the production of graduates with types of knowledge and skills required by markets in society. This system resulted in the clustering together of institutions with a range of mandates pursuing coherent and more explicitly defined educational and social purposes with respect to the production of knowledge and an emphasis on successful graduates (CHE 2000, 64). Accordingly, institutional mandates provide the framework within which 'specific institutional missions and strategies' can be developed to ensure diversity within the proposed differentiation (CHE 2000, 34). In particular, more diversity was envisaged in order to serve the needs of the labour market, offer more and better access to a larger student body, and allow institutional specialisation by which the effectiveness of the overall HE system would increase (Republic of South Africa 2014).

Three types of institutions have been created to implement differentiation and diversification in the post-apartheid setting, namely, universities, technikons (called 'universities of technology' or UoTs) and 'comprehensive' institutions, which would be a hybrid of both. Within this broad three-fold institutional framework, universities would focus on niche areas of 'traditional' general formative and professional undergraduate and postgraduate programmes and research; Universities of Technology would emphasise career- 
oriented programmes, mainly at the undergraduate certificate and diploma levels, as well as offering, with government approval, undergraduate and postgraduate degree programmes in identified areas of strength; and comprehensive institutions would offer a combination (Republic of South Africa 2014, 7).

This type of differentiation of purposes of institutions in terms of knowledge and skills produced has been consolidated by the Higher Education Qualifications Framework (HEQF) that introduced knowledge types and skills produced in universities, different from those produced in UoTs, as criteria for deciding the distinctiveness of institutions (DoE 2007). The HEQF (DoE 2007) distinguished between two modal types of curriculum and qualification; one to produce disciplinary knowledge and therefore, formative or research-based, and the other to produce knowledgeable professionals and thus oriented more specifically to the demands of the workplace (Muller 2009, 14, 2014).

In resonance with the Fordist type of differentiation and specialisation in economic production, higher education has historically been categorised, classified or clustered by legislation in terms of purposes and specialisations in the production of knowledge and skills. Accordingly, some institutional types focus on production and specialisation in applied knowledge for specific occupational careers and professions, while others are assigned to the production of conceptual, theoretical knowledge of different disciplines (DoE 2007).

However, the South Africa Technology Network (SATN) (2008), which represents new UoTs, warned against the tendency to over-simplify their distinctiveness within the differentiated system in South Africa. It argued that differentiation should not be seen as being inferior, but as a tool that helps the sector to identify and focus on niche areas of strength. Thus, SATN conceded that the UoT sector is still at an early stage of redefining its focus to align with the demands of a developing South Africa and with its university status. It argues that perhaps the recognition of UoTs as universities should be seen as an evolutionary process, and that the differentiation debate might still be premature (SATN 2008). The SATN's misgivings about perception of distinctive features of institutional types in South Africa were initially articulated by the CHE as a warning of the prevailing perception that since UoTs now have university status, little differentiation should exist in the functions of teaching/learning, research/innovation, and community engagement (CHE 2010, 174). In seeming acknowledgement of distinctiveness and the overlaps between the purposes of UoTs and traditional universities, CHE argue that 'not all the characteristics and attributes holistically differentiate UoTs from other institutional types’ (CHE 2010, 174). 


\section{DISCUSSIONS AND CONCLUSION}

Earlier conceptions of differentiation, diversification and specialisation (Smithian approach) and the more nuanced flexible differentiation and specialisation (neo-Smithian approach) have been at the heart of all developed and developing societies, defining their productivity and economic growth, the state of their health and welfare, their quality of life, and their cultural and political institutions. We argue that policies and practices in higher education have drawn on both Smithian and neo-Smithian notions of differentiation, diversification and specialisation, albeit implicitly. Thus, universities and higher education in general are aspects of this process, with their focus being on the production and transmission of higher level knowledge. In seeming emulation of earlier conceptions of differentiation and specialisation in economic production, institutions have, over time, been clustered or differentiated as research-based institutions with the purpose of producing knowledge required nationally and internationally, while other institutional types are required to specialise in offering programmes that relate to demand by regional and local industries.

The unspoken assumption underpinning the distinctive boundaries between institutional types alluded to above is the division of labour by which different institutions are legally mandated to specialise in the production of different types of knowledge and skills required in societies. The silent endorsement of some form of division of labour in higher education globally, and in parts of South Africa, has created research-based institutions expected to specialise in the production of conceptual knowledge and skills through research and innovation. In a seeming endorsement of the division of labour in higher education in South Africa, comprehensive universities have been created to specialise in teaching, while UoTs have essentially been assigned the responsibility of specialising in the production of applied knowledge and skills oriented toward regional missions and mandates. Thus, differentiation assumes continuing specialisation, the maintenance of boundaries and the distinctiveness of vocational and university education, as well as the hierarchical relationship between them that their separation implies (see Young and Moodie 2012).

In a seeming resonance with transformations in economic production however, there has been a growing argument for flexible differentiation and specialisation in higher education in response to the emergence of similarities between different occupations, knowledge and skills in the neo-Smithian and post-Fordist era. Thus, increasing support for flexible differentiation and specialisation education is embraced because it is considered most appropriate in ensuring the supply of 'generically skilled' workers able and willing to move to new jobs, regions, countries, industries and services when they arise. 
Three issues on differentiation and specialisation relate to whether graduates should be prepared for and acquire specialised knowledge and skills required by specific markets and trades in particular contexts, or whether they should offer knowledge and skills that would enable them to function in diverse and changing markets and industry, both locally and globally. Another issue relates to support for the retention or abolition of epistemological boundaries between knowledge and skills provided in classical universities, compared to those offered by other tertiary institutions, such as UoTs in South Africa.

Our view on the two issues is that while specialisation to advance conceptual knowledge in specific disciplines is necessary, the tendency to narrow specialisation when graduates acquire knowledge and skills for specific market and jobs in certain contexts is short-sighted. Thus, over-specialisation prevalent in some institutions denies graduates the opportunity to acquire the conceptual and theoretical knowledge and skills they need, in order to function effectively in diverse contexts and in the current environment characterised by emerging similarities between different occupations, knowledge, and skills. Regarding epistemological polarity of knowledge boundaries offered by the different intuitional types in South Africa for example, we concur with the view that theoretical knowledge is necessary to equip graduates with the necessary intellectual and academic tools to participate in societies' conversations and in the debates shaping the field of practice for which they are being prepared (see Wheelahan 2010, 7).

While differentiation and diversification could theoretically address elitism, promote access, and facilitate wider participation and mobility in higher education, current policies that have created differentiated institutions have the potential to recreate previous inequities and inequalities in societies. In South Africa, differentiation and specialisation have, in some cases, recreated past racial and ethnic stereotypes that existed prior to the 1994 democratic elections and the subsequent reconfiguration of higher education. Differentiation policy during this period created historically advantaged Institutions (HAIs) and technikons that served the white section of the population, and historically disadvantaged Institutions (HDIs), universities and technikons that served the black communities. The latter were located in a 'homelands' system by which African black communities were forcefully removed from what were considered 'white spots', furthering the government policy of the ethnicity and tribal origins of Africans of 'separate but equal'.

Similarly, current differentiation and specialisation policies in the post-apartheid setting reproduce and sometimes recreate past racial, ethnical and geopolitical frameworks of the past system, albeit implicitly. The ethnic dimension masquerading as differentiation practices in a 
post-apartheid setting is reflected in the profiles of senior management of universities, academic staff and students. These implicitly reflect the previous ethnic and racial orientations of senior management, as well as the ethnic and regional profile of students. Given the inherited privileges of HAIs gained from the past policy of segregated higher education, the current location of HEIs in provinces essentially reflect the previous geopolitical locations of the regionally, racially and ethnically segregated society. Consequently, the current differentiation policy essentially recreates and reproduces the past inequities that it sought to redress.

Imperatives of equity are undermined when the burden of providing education to the masses, comprising academically unprepared students from disadvantaged communities and townships, and informal settlement schools in South Africa, becomes the sole responsibility of HDIs, comprehensive institutions and new UoTs in the current differentiation system. HAIs are, on the other hand, selective and admit only a few students with good grades from high schools around the country.

Likewise, some contradictions and the efficacy of the current differentiation policy in the post-apartheid setting have emerged since the 1994 democratic elections. We argue, for example, that this policy is caught between political and social imperatives of redressing past inequities between HEIs that bring with them a legacy of past policies and responses to the demands and requirements of the global and knowledge society. Accordingly, this policy is a weak strategy to address historical inequities between institutional types and the production of knowledge and skills required for the knowledge society since its introduction in 2000 (see CHE 2000; DoE 2007).

Currently, types of institutions globally are expected to fulfil a wide range of new roles and tasks that transcend the traditional functions of teaching, mainly in response to the demands of the knowledge society. The changing roles and functions of traditional universities have necessitated the gradual dismantling of the rigid boundaries between universities responsible for research, and other tertiary institutions that concentrate mainly on teaching. However, we argue that HEIs are neither neutral nor stable with regard to where on this continuum their mission (teaching and research) is positioned. The reality is that actual reasons are partly natural (a human inclination toward prestige), partly historical/cultural (historic origins of the classical universities), and in part a function of policy (governmental rewards, whether intended or not, that favour the classical research model, relative to all others) (Johnstone 1998). Therefore, the newer universities have carefully assessed the benefits of being involved in research, compared to the few or no benefits of teaching.

Some lessons from our discussion are: first, 'mission drift' which is more pronounced in 
legally mandated boundaries between the different institutional types and where there is generally low public opinion of institutions mandated to offer undergraduate programmes and focus teaching. These institutions in South Africa include the newly formed UoTs, HDIs and, recently, the Technical Vocational Education and Training (TVET) colleges. Second, drifting towards highly reputable institutions, leading to more homogeneity, could also be attributed to the current situation in which research is used as the exclusive criterion for judging the performances of all institutions, regardless of their mandate (see Van Vaught 2007, 19). This practice further promotes institutional competition by which the differentiation policy is explicitly envisioned to discourage.

Thus, new UoTs in South Africa will unlikely drift towards the missions of traditional research universities if the former were compared to one another and assessed in terms of their respective regional and local mandates and not to research-based institutions. Rather than simply wishing to emulate traditional universities, comprehensive universities and UoTs have calculated the benefits of engaging in research, and therefore drift towards the missions, and specialisations of research institutions. The Brazilian model, in which all institutions operate as teaching institutions, and where there is little gain from taking on the designation of a university, is sound and could be tried in South Africa. We argue further that emphasis should be placed on the distinctiveness of different institutional types, rather than on differentiation as a strategy to deal with 'mission drift' in the country's current differentiated system.

Third, 'mission drift' is also inspired by increasing private contributions to higher education and entrepreneurship that manifest in the form of raising a third-stream income from external funders and industries. Accordingly, institutions frequently drift from their original missions and mandates and creep into those of others, by for example, offering programmes originally assigned to others institutions, by for example engaging in research even if the required expertise and person power do not exist. Similarly, all institutional types regularly engage in entrepreneurship as a survival strategy to offset institutional competition induced by the commercialisation of higher education. Thus, mission drift becomes prevalent in the current environment as institutions are forced to become entrepreneurial by seeking to generate stream income from business, not only to make profit but also to survive global economic austerities.

Lastly, it is necessary to distinguish mission drift in systems with legally mandated boundaries, differentiation and specialisation, and in systems in which the boundaries are not necessarily legally mandated. An interesting contradiction emerges in this regard, as we agree with the view that legally mandated boundaries in higher education systems help to preserve some level of diversity but note that policies that offer more autonomy to HEIs unintentionally 
encourage institutions to emulate one another (see Van Vaught 2007, 12).

\section{REFERENCES}

Allais, S., D. Raffe and M. Young. 2009. Researching NQFs: Some conceptual issues: Employment Sector Employment Working Paper No. 44. Geneva: International Labour Office.

Birnbaum, R. 1983. Maintaining diversity in higher education. San Francisco: Jossey-Bass.

Bleiklie, I. 2005. Organizing higher education in a knowledge society. Higher Education 49(1): 31-59.

Carnegie Commission on Higher Education. 1973. The purposes and performance of higher education in the United States. New York: McGraw-Hill.

Castells, M. 1993. The informational economy and the new international division of labour. In The new global economy in the information age; reflections on our changing world, ed. M. Carno, M. Castells, S. Cohen and F. M. Cardoso, 15-43. University Park PA: Pennsylvania State University Press.

Cedefop. 2010. The development of national Qualifications Frameworks in Europe. Luxembourg: Office of the European Union.

Chappell, C., N. Solomon, M. Tennant and L. Yates. 2002. Researching the pedagogies of the new vocationalism. OVAL research. Sydney: University of Technology Sydney (UTS). http://www.umanitoba.ca/unevoc/2002conference/text/papers/chappell.pdf (accessed 12 May 2014).

CHE, see Council for Higher Education

Clark, B. R. 1983. The higher education system. Berkeley, CA: University of California Press.

Cloete, N. and I. Bunting. 2002. Higher education transformation. Assessing performance in South Africa. Cape Town: Centre for Higher Education Transformation (CHET).

Collins, R. 1979. The Credential Society - An historical sociology of education and stratification. New York: Academic Press.

Council for Higher Education. 2000. Towards a new higher education landscape: Meeting the equity, quality and social development imperatives of South Africa in the $21^{\text {st }}$ century. Pretoria: Council on Higher Education.

Council for Higher Education. 2002. A New Academic Policy for Programmes and Qualifications in Higher Education. Pretoria: Council on Higher Education

Council for Higher Education. 2010. Universities of technology - deepening the debate. Pretoria: Council on Higher Education.

Cristopherson, S. and M. Storper. 1989. The effects of flexible specialisation in industrial politics and the labor market. Industrial and Labor Relations Review 42: 331-47.

Department of Education. 1997a. Education White Paper 3: A programme for higher education transformation. Pretoria: Government Printers.

Department of Education. 1997b. General policy for technikon instructional programmes. Report 150 (97/01). Pretoria: Department of Education.

Department of Education. 2001. National plan on higher education in South Africa. Pretoria: Government Printers.

Department of Education. 2007. Higher Education Qualifications Framework. Pretoria: Department of Education.

DiMaggio, P. J. and W. W. Powell. 1983. The iron cage revisited: Institutional isomorphism and collective rationality in organizational fields. American Sociological Review 48: 147-60.

DoE, see Department of Education.

Du Pre, R. 2009. The place and role of universities of technology in South Africa. Bloemfontein: South African Technology Network.

Durkheim, E. 1983. Pragmatism and sociology. Cambridge: Cambridge University Press. 
HSRC, see Human Sciences Research Council.

Huisman, J. 1995. Differentiation, diversity and dependency in higher education. Utrecht: Lemma.

Human Sciences Research Council. 1996. National Commission on Higher Education Report: A framework for transformation. Cape Town: Human Sciences Research Council.

Johnstone, D. B. 1998. Institutional differentiation and the accommodation if enrolment expansion in Brazil. Washington: World Bank.

Jones, A. 2009. Generic attributes as espoused theory: The importance of context. Higher Education 58(2): 175-191.

Kaulich, F. 2012. Diversification vs. Specialization as alternative strategies for economic development: Can we settle a debate by looking at the empirical evidence. Vienna: United Nationals Industrial Development Organization

Kogut, B. and U. Zander. 1993. Knowledge of the firm and the evolutionary theory of the multinational corporation. Journal of International business studies 24(4): 625-645

Lester, S. 2001. The construction of Qualifications Levels and Frameworks: Issues from three UK Projects. Higher Education Quarterly 55 (4): 396-415.

Longanecker, D. A. 2008. Missions differentiation vs missions creep: Higher education battle between creation and evolution. National Conference of State Legislatures. The forum for America's ideas.

Muller, J. 2009. Forms of knowledge and curriculum coherence. Journal of Education and Work 22(3): 205-26.

Muller, J. 2014. Edging closer to differentiation in higher education. University World News Issue No 345 , November.

Neave, G. 1996. Homogenisation integration and convergence: The Cheshire cats of higher education. In The mockers and mocked: Comparative perspectives in differentiation, convergence and diversity in higher education, ed. V. L. Meek, L. Goedegebuure, O. Kivinen and R. Rinne, 26-41. Oxford: Pergamon Press.

Neave, G. 2000. Diversity, differentiation and the market: The debate we never had but which we ought to have done. Higher Education Policy 13: 7-21.

Ng'ethe, N., G. Subotzky and G. Affeti. 2008. Differentiation and articulation in tertiary education systems. A study of twelve African countries. Washington, DC: World Bank.

Ntshoe, I. M. 2014. Essaying purposes and specialisations of institutional types in knowledge production. Studies in Higher Education 40(4): 676-689.

Piore, M. J. and C. F. Sabel. 1984. The second industrial divide. New York: Basic Books.

Powell, J. J. W. and H. Solga. 2010. Analyzing the nexus of higher education and vocational training in Europe: a comparative-institutional framework. Studies in Higher Education 35(6): 705-721

Reich, R. 1991. The work of nations. New York: Vintage Books.

Reichert, S. 2009. Institutional diversity in European higher education. Tensions and challenges for policy makers and institutional leaders. Brussels: European University Association

Republic of South Africa. 2014. Policy framework on differentiation in the South Africa post-school system. Pretoria: Government Printers.

Riesman, D. 1965. Constraint and variety in American education. Lincoln: University of Nebraska Press.

Ross, A. 2003. Access to higher education: Inclusion for the masses? In Higher education and social class: Issues of exclusion and inclusion, ed. L. Archer, M. Hutchings and A. Ross. London: Routledge. Falmer.

SATN, see South African Technology Network.

Scott, P. 2007. Back to the future? The evolution of higher education systems, In Looking back to look forward. Analyses of Higher Education after the turn of the millennium, ed. B. Kehm. Kessel. Wekstattberichte 67.

Smith, A. 1776. The wealth of nations. London: W. Strahan and T. Cadell. 
South African Technology Network. 2008. Final report - The development of performance indicators for universities of technology (UoTs) and UoT related parts of comprehensive universities (CUs). http://www.satn.co.za/wp-content/uploads/2012/10/FINAL-EDITED-VERSION REPORT-ONPI-PROJECT-Revised_251108.pdf (accessed 22 September 2013).

Teichler, U. 2004. Changing structures of the higher education systems: The increasing complexity of underlying forces. Papers produced for the UNESCO Forum Regional Scientific Committee for Europe and North America. Paris: UNESCO, 3-16.

Tolliday, S. and J. Zeitlin. 1987. The Automobile industry and its workers: Between Fordism and Flexibility. New York: St. Martin's Press.

Trow, M. 1974. Problems in the transition from elite to mass higher education. In Organisation for Economic Cooperation Development (OECD). Policies for Higher Education, 51-101. Paris: OECD.

UNESCO. 2004. Diversification of higher education and changing role of knowledge and research. Paris: UNESCO Forum Occasional papers, Series Paper No. 6.

Van Vaught, F. 2007. Diversity and differentiation in higher education systems centre for on higher education transformation anniversary conference. 16 November. Cape Town.

Wheelahan, L. 2010. Why knowledge matters in curriculum. A social realist argument. Abingdon, Oxon. Routledge.

Winch, C. 2006. Georg Kerschensteiner - founding the dual system in Germany. Oxford Review of Education 32(3): 381-396.

Williams, G. 1985. Graduate employment and vocationalism in higher education. European Journal of Education 20(2): 181-192.

Young, M. and G. Moodie. 2012. Differentiation, de-differentiation and collaboration between vocational education and universities. In Higher education in regional and city development. Postsecondary vocational education and training, ed. Jaana Puukka, 67-78. Paris: Organisation for Economic Committee Development (OECD). 